stopcocks are wide open, any adjustment that is considered desirable for the level of the liquid standing higher than the other in its glass tube, may be deliberately made by adrawing out or letting in a little air through the lower air-pump stopcock.

Either or both liquids may be thoroughly stirred at any time to ensure homogeneousness by alternately exhausting and letting in air to the bottle or bottles by means of the air-pump and the lower air-pump stopcock, the upper three stopcocks being kept closed.

Operation No. 6 of my article on the subject, in last week's NATURE (p. 274), must be performed as often as is found necessary. Every one of the stopcocks must be kept closed except when it is open for operation or observation.

The metal tube connecting the upper necks of the two bottles must be long enough, or of fine enough bore, to prevent diffusion of vapour to any sensible extent from either bottle to the other during the time of an observation. It ought to be kept at a temperature somewhat higher than that of the bottles, to prevent any liquid from condensing as dew on its inner surface.

KEI.VIN

Glasgow, January 23.

\section{THE GRAVITATION CONSTANT AND THE MEAN DENSITY OF THE EARTH.}

$\mathrm{I}$ the year 1884 , Prof. Dr. Franz Richarz and Dr. Otto Krigar-Menzel commenced a series of experiments having for their object an accurate determination of the values for the constant of gravitation and the earth's mean density. The work divided itself naturally into two parts, and the results of the first series of weighings were communicated to the Berlin Academy of Sciences in March I893. Since that time the second series has been concluded, and the main results of the whole investigation are summed up briefly in the same society's Sitzungsberichte for November I 896 , the authors leaving the publication of the full account, containing the details of the measurements, for a future period.

The instrument with which the measurements were made was a kind of double-balance having two pans on each side of the beam, one above the other, connected in the vertical direction by a thin rod 226 centimetres long. The point of this arrangement was that the acceleration due to gravity on the two lower pans was greater than that on the upper one, in consequence of the difference of level. The first day's weighing consisted in determining the difference in weight of two practically equal spheres, one being placed in the upper pan on one side of the arm of the balance, and the other in the lower pan on the opposite side. Gauss' system of double weighing was employed throughout, the masses being changed from one side to the other. The measured difference was therefore due to two sources-to the inequality of the masses weighed, and to the difference of the force of gravity. The procedure for the second day was to change the positions of the masses being weighed; this consisted in placing the sphere that was in the upper pan in the lower one on the same side of the arm, and in putting that on the other side of the beam in the upper pan: a second series of weighings was then made. Such a series of measurements as these was included in the work recorded in the first publication. It was found that the measured difference was not the same on the two days, for although the difference in weight of the masses always remained the same, the difference in the value of gravity, due to the virtual displacement of the masses, altered its sign. By subtracting these differences for each day's work, the massdifference was entirely eliminated, and there only remained that between the two values of gravity due to the two heights of the scale-pan.
In the second part of the work, for obtaining the mean density of the earth, a large cubic block of lead, having a mass of 100,000 kilograms, was used. This was supported firmly on massive pillars under the upper and above the lower scale-pans, the connecting-rods of the latter passing through holes in the block. The presence of this great attracting mass had the effect of apparently increasing and decreasing the value of gravity acting on the spheres in the pans according to their position-that is, according as they were in an upper or a lower pan. In the system of arrangement adopted-namely, that of placing the spheres in an upper and lower pan on opposite sides of the fulcrum-the acceleration of gravity in the upward direction was lessened by double the amount of the attraction of this great mass of lead. By connecting to two days' weighings, instead of double the diminution of the value of gravity with the height, the result was lessened by four times the attraction of the block of lead. A combination of the results obtained, both with and without the leaden cube, gave the fourfold attraction of the leaden cube free from the variations of gravity.

Very elaborate precautions were taken to eliminate effects of air currents, changes of temperature, \&c., and these seem to have been fairly overcome both practically and theoretically. It is also needless to state that the number of weighings made was very considerable.

The value thus finally deduced for the constant of gravitation was

$$
\mathrm{G}=(6 \cdot 685 \pm 0 \cdot 0 \mathrm{II}) \mathrm{IO}^{-8} \frac{\mathrm{cm}^{3}}{\text { gr. sec. }{ }^{2}}
$$

Using this value, the mean density of the earth obtained was as follows:-

$$
\Delta=(5.505 \pm 0.009) \frac{\mathrm{gr} .}{\mathrm{cm}^{3}}
$$

This value, as will be seen from a perusal of the following table, falls between those found by Poynting and Boys :-

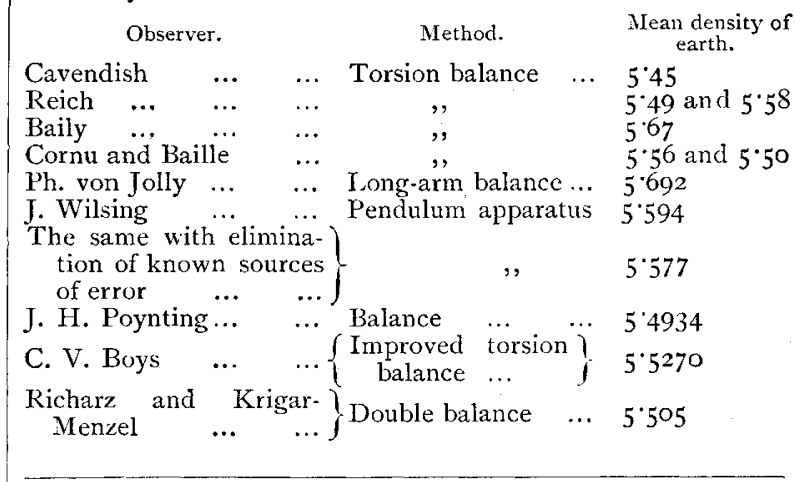

TUBES FOR THE PRODUCTION OF RÖNTGEN $R A Y S$.

MANY and various are the forms of the bulbs and tubes employed for the production of Röntgen rays, as may be seen from the designs that are represented in the accompanying illustration from La Nature. Different experimenters favour different tubes, and believe that the forms they use possess advantages over all others. Up to the present, however, it may be said that three processes are utilised in the production of Röntgen rays. There is ( 1 ) the old form of Crookes' tube, in which the kathode rays impinge directly upon the glass or screen in front of the kathode ; (2) the form of tube in which the kathode rays fall upon, and are refiected by the anode; and (3) the tubes in which both direct and reflected rays are utilised. In the accompanying illustration, the first 
method is exemplified by Nos. I, $2,3,4,6,7$, IO, I I, I 2 , I $3,14,17$, I $8,20,2 \mathrm{I}, 24,26,28,32$; the second system, by the adoption of which instantaneous Röntgen photography became possible, is adopted in the tubes numbered $5,8,9,15,16,23,25,27,29,30$; and the third principle is illustrated by Nos. I9, 22, 3I. The Crookes' tube, represented by No. I, is very well known, and is still used for Röntgen photography on the continent. No. 2 represents a form of tube used when the movement of the kathode stream by a magnet is desired, so that the rays can be made to impinge upon different parts of the glass. In No. 3, the concave kathode is brought very near to the glass, so that its focus is really outside. No. 4 shows a tube with a kathode which can be revolved in a plane at right angles to its own face. No. 5 has two kathodes, and the rays from them are reflected from a platinum anode. In No. 6 the anode is formed of an aluminium disc, which is traversed by the kathode rays; but the advantages of this form are not very clear. Two kathode streams are utilised in No. 7. The form of tube which workers in this country find gives the best results, is represented in No. 8, and is known as the "focus" tube, or tube of Jackson pattern. In this the kathode rays fall upon, and are reflected by, a platinum mirror which forms the anode. No. 9 has two anodes, one of them a hollow platinum cone which reflects the kathode rays. The tube shown in No. Io is especially suitable for use with currents of high frequency; it is uni-polar, and has an external anode. No. II has pointed poles, either of which may be the kathode. The tube No. I 2 has a platinum kathode, covered on its convex side by a glass insulator so as to reduce the loss of radiation. No. 13 is found to give good effects on fluorescent screens. No. I4 is for use with currents of high frequency, and has only one pole in the tube. No. 15 is a useful form of tube, one of its advantages being that two photographs can be taken at the same time by the reflection of the rays from the kathode on either side. In the tube represented by No. Ió, a circular disc forms the kathode, and at its centre is set a hollow cone of platinum as an anode. No. I7 represents a form of tube for the investigation of the action of kathode rays upon a substance. The end of the cylinder is made so that substances can be introduced into the tube. Another kathodic cylinder is shown in No. 18 ; the kathode is situated at the place usually occupied by the anode, the latter pole being at the top. No. ig combines the actions of both the direct and reflected rays. The kathode passes through a concave anode of platinum, and all the rays emitted by it are utilised either directly or after reflection. A cylinder employed at the commencement of work with kathode rays is shown in No. 20 ; a good point about it is that the poles are some distance apart, so there is little fear of sparking outside the tube. A cylinder with an interchangeable window opposite the kathode is represented in No. 21. A tube with two anodes (No. 22) is designed on the principle of the reflection of the kathode rays, the kathode being placed centrally inside a reflecting anode. Another bi-anodic form is the large bulb shown in No. 23. The next figure (No. 24) has slips of aluminium as poles, and either of them may form the kathode. No. 25 NO. I 422 , VOL. 55$]$ is constructed so that the platinum cone which forms the anode, reflects the rays from four kathodes placed around a circumference, and kept in action by as many coils. A tube, useful for showing the place of origin of active rays, is shown in No. 26. The next (No. 27) has two anodes and two kathodes; the two kathode streams are reflected from the anodes, and, meeting one another, are given additional power. No. 28 resembles No. Io, but it has the defect that it rapidly becomes heated. In No. 29 the kathode is formed of an annular aluminium plate, the rays from which strike upon the central platinum

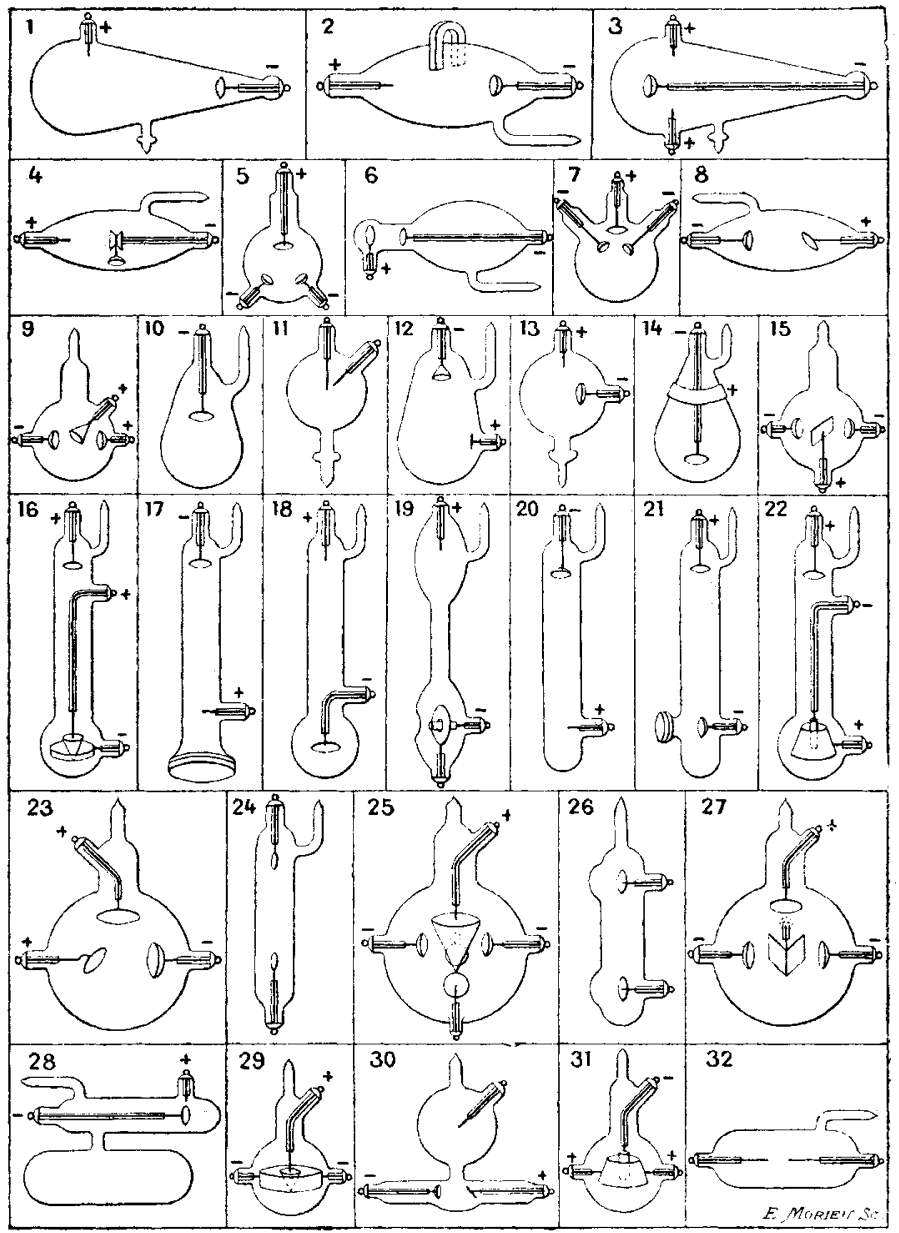

FIG. I.-Fiorms of tube used for the production of kathode and X-rays. I, 2, Crookes' tube; 3 , Séguy tube; 4 , Wood tube ; 5 , Séguy tube; 6 , Chabaud and Hurmuzescu tube; 7 , Séguy tube ; 8 , "Focus" tube; 9 , Séguy tube; ro, d'Arsonval tube II, Séguy tube; $x_{2}$, Puluj tube; I $_{3}$, Séguy tube; I4 $_{4}$ d'Arsonval tube; 15 , Le Roux tube ; $16,17,18$, Séguy tubes; ro, Rufz tube; 20 , Crookes' tube ; $21,22,23$, Séguy tubes; 24, Röntgen tube ; 25, Brunet-Séguy tube; 26, 27, Le Roux tubes; 28, Colardeau tube; 29, Séguy tube; 30 , Colardeau tube; 31 , Séguy tube; 32 , 